Portland State University

PDXScholar

Communication Faculty Publications and

Presentations

Communication

$1-1-2003$

\title{
Categories and Similarities: A Note on Circularity
}

L. David Ritchie

Portland State University, cgrd@pdx.edu

Follow this and additional works at: https://pdxscholar.library.pdx.edu/comm_fac

Part of the Communication Commons

Let us know how access to this document benefits you.

\section{Citation Details}

Published as: Ritchie, D. (2003). Categories and similarities: A note on circularity. Metaphor and Symbol, 18(1), 49-53.

This Post-Print is brought to you for free and open access. It has been accepted for inclusion in Communication Faculty Publications and Presentations by an authorized administrator of PDXScholar. Please contact us if we can make this document more accessible: pdxscholar@pdx.edu. 
Running head: $\quad$ CIRCULARITY

\author{
Categories and Similarities: A Note on Circularity \\ David Ritchie \\ Portland State University
}

Address correspondence to:

David Ritchie, Professor

Department of Communication

Portland State University

Portland, OR 97202-0751

(503) 725-3550

fax: (503) 725-5385

e-mail: cgrd@pdx.edu

Metaphor and Symbol, 18(1). 2003. 


\begin{abstract}
Theories of metaphor comprehension that rely on category assignment based on common characteristics (Keysar \& Glucksberg, 1992), a comparison between characteristics or relationships of source and target (Chiappe \& Kennedy, 2001), or a mapping of characteristics or relationships from source to target (Gentner \& Bowdle, 2001) are inherently circular, since these comparisons, mappings, or categories usually make sense only after the underlying metaphor has already been understood. This inherent circularity is avoided by approaches such as conceptual metaphor theory (Lakoff \& Johnson, 1980) and conceptual blending theory (Fauconnier \& Turner, 1998) that seek to explain metaphors in terms of underlying cognitive concepts or schemas.
\end{abstract}




\section{Categories and Similarities: A Note on Circularity}

Glucksberg and Keysar (1993; Keysar \& Glucksberg 1992) propose that a metaphor establishes a superordinate category to which both vehicle and topic belong, based on having the relevant qualities. For example, "Cigarettes are time bombs" establishes a category of objects that seem harmless at first but are eventually deadly, “Sermons are sleeping pills" establishes a category of objects that induce sleep, and "My job is a jail” places "my job” into "the category of things that the metaphor vehicle jail typifies - situations that are unpleasant, confining, difficult to escape from, unrewarding, and so on” (Glucksberg, Keysar, \& McGlone, 1992, p. 578). This account has been disputed by Chiappe \& Kennedy (2001), who argue that, when a metaphor is compared to the related simile, it is to a large extent irrelevant whether we classify the metaphor as part of a superordinate category. Continuing with the example, “Jobs are jails,” Chiappe and Kennedy claim that the interpretative realization "is not what the ad hoc category is... Rather, the work of comprehension is done by determining properties that make up the ad hoc category... people would likely infer that the relevant properties include the predicates, 'constraining,' ‘confining,' and 'where people are held against their will.’”

A closer examination of the metaphors provided as examples suggests that, for many metaphors, both of these accounts lead to circularity. Cigarettes and time bombs share the literal quality of leading eventually to death (not metaphorical death but real, heartbeat stops, life insurance pays off, death), and at least some sermons share with sleeping pills the literal quality of inducing sleep (not metaphorical sleep but real, eyes closed and snores emitted sleep), but jobs do not ordinarily share any of the qualities that define a jail. In the absence of outright slavery (and excepting the sort of sweat-shop 
operations that periodically crop up in the garment industry), workers are not physically confined, locked up, shackled, or forced to remain against their will: The sense of confinement and constraint is wholly metaphorical. Jobs do not share the qualities that define jails in any literal sense, but only in a sense that is already metaphorical. For metaphors of this sort, both "superordinate categories" and "common properties" lead to a circular definition, inasmuch as they both rely on qualities that pertain to the vehicle literally but to the topic metaphorically. These qualities cannot be considered either “common” or "category-defining” until after the metaphorical work has already been accomplished.

Consider another example, from Keysar and Glucksberg (1992), “This encyclopedia is a jungle." A jungle is prototypical of "things that are tangled, humid, and difficult to get through," but an encyclopedia is not the sort of thing one can "get through" without physically destroying it, and if it is either "tangled" or "humid," it has already been physically destroyed. Before an encyclopedia can be considered "tangled, humid, and difficult to get through,” and thus added to the category of which a jungle is a prototype, these qualities must be metaphorically interpreted, and a metaphorical category created around them. At least some of the metaphorical work required to establish the similarities and define the superordinate metaphorical category can be accomplished by conceptual metaphors (Gibbs, 1992; Lakoff \& Johnson, 1980; 1999), for example, “UNDERSTANDING IS PHYSICAL MOVEMENT” and “CONFUSING IDEAS ARE TANGLED STRINGS." Neither the identification of "common properties" nor the creation of a superordinate category can be the basis for understanding the metaphor, because these properties can only be understood as common, and the 
superordinate category constructed, after the metaphor has been understood. The identification of similarities and the construction of superordinate categories cannot possibly tell us anything about how people understand these metaphors.

As Keysar and Glucksberg also point out, "This encyclopedia is a jungle" can be reversed to get "This jungle is an encyclopedia." At first glance, "This jungle is an encyclopedia" seems to fare better, since both jungles and encyclopedias fall within a category defined by "things from which one can obtain information." But this example raises another sort of problem, since every object in the universe is a potential source of information, and a category that includes every object in the universe is neither useful nor enlightening. Even this metaphor would seem to require identification of some other qualities that are literally descriptive of encyclopedias, but only metaphorically descriptive of jungles, perhaps matched by some quality of jungles that set them apart from vacant lots and soccer fields and thus make them particularly well-suited to be called "encyclopedias."

Likewise, it is not strictly the quality of causing death that makes "cigarettes are time bombs" interesting nor strictly the quality of causing sleep that makes "sermons are sleeping pills" interesting. Some other quality, perhaps the ironical reassignment of intentionality, creates the humorous tension of these two metaphors. Category assignment may play a role in these metaphors, but even here it doesn't seem to account satisfactorily for the way the metaphors work. The only metaphors I can think of where category assignment seems to provide an adequate explanation are physical resemblance metaphors like "table leg," in which both human and table appendage are members of the 
category of "long thin things that support weight." But "table leg" is arguably an example of metonymy rather than metaphor.

To resolve the apparent contradiction between comparison and categorization, Gentner and Bowdle (2001) propose a "career of metaphor” theory, based on structuremapping, but structure-mapping also depends on circularity. In their example, “men are wolves," the scenario, "men prey on women," can be mapped onto "wolves prey on animals” only after the metaphorical relationship between [stalk, kill, eat] and [seduce, have sexual intercourse with, abandon] has been established (and there is nothing at all intuitively obvious about this relationship). Gentner and Bowdle acknowledge that "the way in which men prey on women is different from the way wolves prey on animals" (2001, p. 227), but it is precisely this difference that constitutes the metaphor! To understand the immensity of the difference, consider that men literally prey on many of the same animals wolves prey on: Every autumn, men [stalk, kill, and eat] deer, elk, and antelope. With exceptions such as the fictional Hannibal Lecter (Demme, 1991), when men "prey on" women, it is in a sense that is already metaphorical. (Even Lecter's actions are arguably metaphorical, since they have a quality utterly different from the wholly natural relationship of wolves and mountain lions to deer and elk.) The quoted sentence ends with "Men chase after women for sexual gain, whereas wolves hunt other animals for food” (Gentner \& Bowdle, 2001, p. 227). But "predatory” seductions are more likely to involve soft lights and champagne than a footrace (the mythical Atalanta and Melanion notwithstanding); "chase after" is itself metaphorical, part of the "wolves" and "prey upon" metaphor system (which also includes "wolf whistle" and "wolf pack" pornographic playing cards). Structure-mapping theory has some utility in helping us to 
understand the creation of entailments (“candidate inferences”), but it is of no use in explaining the actual interpretation of metaphor. This circularity does not necessarily invalidate Gentner and Bowdle’s (2001) “career of metaphor” theory, but it does point up the need to develop a more careful explication of the interpretation process.

In general, neither category assignment nor the identification of shared properties can play a primary role in metaphor theory, since many metaphors (most of the more interesting ones, I would venture) require interpretation before any shared qualities or common category membership can be identified - and other metaphors seem incompletely understood even after the identification of shared qualities and common category membership. The most we can say is that metaphorical properties are identified by preexisting conceptual mappings and, perhaps, that metaphorical categories are built up around these same preexisting conceptual mappings (Gibbs, 1992). Men seducing, then abandoning, women can be expressed in terms of wolves killing and eating deer because the emotional and social meanings associated with a feeling of helplessness and objectification in the face of single-minded and relentless sexual attentions is already mapped onto our cultural image of wolves. An onerous and unrewarding job can be expressed in terms of jail because the emotional and social meanings associated with a feeling of being committed to an unpleasant situation is already mapped onto our cultural image of jails and prisons. These pre-existing mappings may create the respective categories of feeling helpless or objectified in the face of single-minded and relentless sexual seduction, and feeling oppressed by a commitment to an unpleasant situation, to which new experiences can readily be assigned ("a singles bar is a meat market," "He just stood there, panting over my bod," "He is a real woman chaser"; "she was 
imprisoned in a loveless marriage," "I'm afraid I'm locked in to going hiking this weekend”).

Lakoff and Johnson (1980; 1999) explain the metaphorical mapping process in terms of underlying concepts, claiming that we actually experience the target concept in terms of the source. Thus, an exasperated worker who complains, "This job is a jail" is inviting the listener to experience the supervisor as a prison guard, the workplace as a barred cell, the employment contract as a sentence, and so forth. A more general account, that subsumes Lakoff and Johnson’s “conceptual metaphors,” is provided by conceptual blending theory (Fauconnier \& Turner, 1998; 2002). In brief, Fauconnier and Turner argue that the conceptual structures of two or more "input spaces" (e.g., target and source) are selectively combined into a new, separate, "blended” mental space (the metaphor). These blended mental spaces are then available for further blending. Thus, for example, "men are wolves" combines the schema of men who are single-minded and emotionally uninvolved in pursuit of sexual gratification with a pre-existing schema of wolves as heartless and vicious predators, itself a prior blend of various terrors once associated with life at the edge of a wilderness with the observed and imagined behavior of actual wolves in pursuit of their prey. Similarly, "My job is a jail" blends the mental image of my working conditions as I experience them with a pre-existing schema of jail, itself a blend of various emotions associated with social and physical constraints with mediated accounts of life in a jail or prison.

In sum, theories of metaphor comprehension that rely on a comparison between characteristics of source and target, a mapping of characteristics or relationships from source onto target, or assignment of target to a category typified by the source are 
circular: They assume a comparison that is already metaphorical. In order to achieve a satisfactory explanation of how metaphors are interpreted and understood, it is necessary to explain how the crucial, salient aspects of an experience (emotional, social, perceptual, etc.) associated with the target can be evoked by linking it to the source. Both conceptual metaphor theory (Lakoff \& Johnson, 1980; 1999) and conceptual blending theory (Fauconnier \& Turner, 1998; 2002) represent movements in the right direction. 


\section{References}

Chiappe, D. L., and Kennedy, J. M. (2001). Literal bases for metaphor and simile. Metaphor and Symbol, 16, 249-276.

Demme, J. (Director). (1991). The Silence of the Lambs. [Film]. Columbia Tristar Pictures.

Fauconnier, G., and Turner, M. (2002). The way we think: Conceptual blending and the mind's hidden complexities. New York, NY: Basic Books.

Fauconnier, G., and Turner, M. (1998). Conceptual integration networks. Cognitive Science, 22(2), 133-187.

Gentner, D., and Bowdle, B. F. (2001). Convention, form, and figurative language processing Metaphor and Symbol, 16, 223-247.

Gibbs, R. W., Jr. (1992). Categorization and metaphor understanding. Psychological Review, 99, 572-577.

Glucksberg, S., and Keysar, B. (1993). How metaphors work. In A. Ortony (Ed.), Metaphor and thought ( $2^{\text {nd }}$ ed, pp. 401-424). Cambridge, England: Cambridge University Press.

Glucksberg, S., Keysar, B., and McGlone, M. S. (1992). Metaphor understanding and accessing conceptual schema: Reply to Gibbs(1992). Psychological Review, 99, 578-581.

Keysar, B., and Glucksberg, S. (1992). Metaphor and communication. Poetics Today, 13(4), 633-658.

Lakoff, G., and Johnson, M. (1980). Metaphors we live by. Chicago, IL: University of Chicago Press.

Lakoff, G., and Johnson, M. (1999). Philosophy in the flesh: The embodied mind and its challenge to western thought. New York NY: Basic Books. 